It hangs on the wall across the room from a projection of almost 2,000 digitized cryosections that make up part of the US National Library of Medicine's Visible Human Project; they were taken from a Texan mechanic who received the death penalty for murder in 1993. The exhibition also includes a copy of the Guidance for the Care of Human Remains in Museums 2005. Appropriately, a funeral effigy from Vanuatu in the South Pacific, known as a rambaramp, contains the skull of its subject but is displayed with the permission of the community from which it was collected.

The idea that we all have multiple bodies, each made visible by the technologies used to explore them, is expressed in five lifesized body maps created by the Bambanani Women's Group in South Africa to document their experience of living with HIV/AIDS and its treatment. Within an outline tracing of her own body, each woman has illustrated her feelings about what is going on inside it, mixing biomedical, social, religious and moral perspectives.
Hanging above the central atrium is Jim Bond's Anamorphic Man. The parts of the sculpture, constructed of steel wire at vastly differing scales, appear disjointed and meaningless until the viewer moves to the single viewpoint from which the assembly coheres as a human figure. Assembling Bodies achieves the same trick, offering visitors an opportunity to make sense of the human enterprise of exploring and representing their material selves. Georgina Ferry is a writer based in Oxford, UK, and author of Max Perutz and the Secret of Life.

\title{
Science journalism: From the newsroom
}

\section{The Washington Post's national environmental reporter Juliet Eilperin and its executive editor Marcus Brauchli discuss the future of science coverage in their newspaper.}

JE: Like many news organizations, declines in advertising dollars and profits have led to The Washington Post losing dozens of reporters and editors in the past five years through early retirement offers - four on the science beat alone. How is that changing things?

MB: The most obvious effect is that we're getting by with fewer people and being more selective in committing our resources. We're also creating a new health, science and environment unit headed by Frances Stead Sellers, who will oversee a team of reporters covering these subjects nationally and locally. This will eliminate the old divisions in our newsroom and provide stronger, bettercoordinated coverage online and in the paper.

JE: How do you think science news stories have changed as a result?

MB: We're steering away from reporting just the facts towards analysis and contextual coverage that helps readers to understand crucial issues. We need to explain what's happening, but we also need to tell general readers and policy-makers what some event or discovery means. This is where we can bring a level of expertise to science coverage that most news organizations cannot.

The biggest challenge is to avoid bias. Yes, we encourage analysis and expertise from our writers; no, we don't want to use our interpretative skills and authority in a way that undermines our commitment to being open-minded and fair.

JE: For years, embargoed scientific papers have driven the news cycle. Should we be moving away from this sort of coverage to emphasize unique content instead?

MB: We'll continue to cover important scientific papers - and we'll always endeavour to put them in context, bringing the expertise of our science writers to the issues, rather than reporting on a single study's findings. But we also have to make choices: sometimes we'll run copy from the newswires rather than using our writers' time to cover something everybody else is covering. We've got a team of skilled reporters and we want to devote their energies to coverage that enhances the Post's mission to be for and about Washington - to serve the people and policy-makers who live and work here.

JE: That sounds as if there should be a heavy emphasis on political stories.

MB: Two of the biggest political stories this year are essentially scientific - climate change and

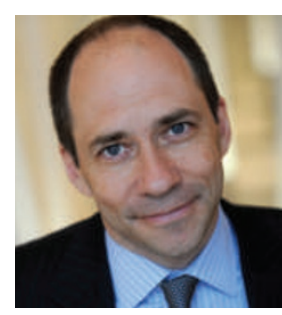

the Internet - things that move at great speed - and you might think of science as being well suited to that. But it can be incremental, too.

Look at the swine-flu story. Within hours, the blog we put together was packed with compelling coverage, fed by reporters from across the newsroom. The rapid pace of new developments - a flu case here, a school closed there - is well suited to the speed of the Internet, but then you have to guard against sensationalism, against making each advance seem more important than it

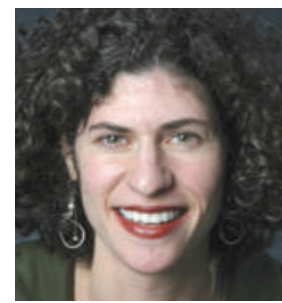

Marcus Brauchli (top) and Juliet Eilperin. is. At the same time there is a slower, incremental process of gathering information about what the virus is, or how dangerous it may become. This isn't as suitable for the web, but both trajectories need to be reported. health reform. Science is all about

JE: Do you think the web changes how stories are told?

how we live, and you can't separate that from culture or politics.

JE: News organizations are devoting more resources to their web products - your online edition now has more readers than the print edition, and you're integrating the two staffs. Do you see a distinctive place for science coverage in that transition?

MB: The ability to reach and inform readers immediately through the web is both an advantage and a huge challenge for science writing. Science created computers,
MB: Good science coverage is about much more than writing a single story; it's about using graphics to explain difficult concepts and procedures, being ready to answer readers' questions online, and using video and photo galleries to enhance our traditional storytelling. Good science writing entertains readers even as it informs them. Juliet Eilperin and Marcus Brauchli are at The Washington Post, Washington DC 20071, USA.

See Editorial, page 1033, and online at www.nature. com/news/specials/sciencejournalism. 